\title{
Enhancement of near-annual variability in the equatorial Pacific in 2000-2008
}

\author{
O. Fashé ${ }^{1}$ and B. Dewitte ${ }^{2}$ \\ ${ }^{1}$ Universidad Nacional Mayor de San Marcos, Facultad de Ciencias Físicas, Dept. de Física Interdisciplinaria, Lima, Peru \\ ${ }^{2}$ Laboratoire d'Etudes en Géophysique et Océanographie Spatiales, IRD/CNRS/UPS/CNES, Toulouse, France
}

Correspondence to: O. Fashé (ofasher@gmail.com)

Received: 18 May 2011 - Revised: 8 September 2011 - Accepted: 1 October 2012 - Published: 2 April 2013

\begin{abstract}
Like the El Niño Southern Oscillation (ENSO), the near-annual mode is an air-sea coupled mode of the tropical Pacific that can emerge within a relatively cool mean state. It is documented here from satellite observations over the 2000-2008 period based on a covariance analysis between wind stress and zonal current anomalies. It is shown that near-annual variability is enhanced over the last decade. The signature of this mode consists of a zonal seesaw pattern for zonal current with westward (eastward) anomalous currents in the western (eastern) equatorial Pacific. A composite analysis allows identifying the peak and transition phases of this mode, particularly active over 2000-2004. It is suggested that the reduction of the interannual variability in the eastern Pacific over the last decade may be related to the enhancement of the near-annual mode.
\end{abstract}

\section{Introduction}

The variability of the tropical Pacific Ocean is mainly dominated by the El Niño Southern Oscillation (ENSO) (Philander, 1985, 1990). ENSO results from the strong air-sea interaction in the central Pacific near the eastern edge of the warm pool, where anomalous sea surface temperature (SST) can drive intense fluctuations in zonal wind stress. Besides ENSO, the tropical Pacific is also the siege of oceanic variability at a variety of timescales, from decadal (Tourre et al., 1999; Zhang et al., 1999), biennials (Ropelewski et al., 1992) to intra-seasonal (Dewitte et al., 2008). These modes may eventually interact with ENSO and participate in the so-called ENSO modulation which designates the change in ENSO characteristics (mostly frequency and amplitude) at low frequency (Timmermann et al., 2003; Cibot et al., 2005;
Rodgers et al., 2004; Sun and Yu, 2009). Another mode of variability that interacts with ENSO is the seasonal cycle of the tropical Pacific. Although having a weaker amplitude than ENSO, its role in the former has proven to be critical for explaining some of its characteristics, like the seasonal ENSO predictability barrier (Flügel and Chang, 1998; Jin et al., 2008), its seasonal phase locking (Neelin et al., 2000; Galanti and Tziperman, 2000) and even its chaotic character (Jin et al., 1994).

ENSO has apparently experienced a change in characteristics in recent years. In particular, the interannual variability has increased in the western Pacific with an increased occurrence of the so-called Modoki El Niño (Ashok et al., 2007; Yeh et al., 2009; Lee and McPhaden, 2010). Relatively, the interannual variability has decreased in the eastern Pacific where the seasonal cycle of SST has its largest amplitude. These changes imply that the ratio of the interannual variability versus the annual variability has drastically changed over the last decade. This is illustrated in Fig. 1, which displays the results of a wavelet analysis of the NINO3 SST index (SST averaged over $150-90^{\circ} \mathrm{W} ; 5^{\circ} \mathrm{S}-5^{\circ} \mathrm{N}$ ) of the Reynolds data covering 1992-2010 and of the satellite-derived zonal current (averaged over $0^{\circ} \mathrm{E}-150^{\circ} \mathrm{W} ; 5^{\circ} \mathrm{S}-5^{\circ} \mathrm{N}$ ). Figure 1a and c clearly show that the dominant timescale of variability after 2000 is the one within the annual frequency band, resulting in an enhancement of the near-annual variability relative to the interannual variability (Fig. 1e).

The near-annual variability in the tropical Pacific can be interpreted as resulting from air-sea interactions similar to that of ENSO (Jin et al., 2003; Kang et al., 2004). There is actually some evidence that there exists a near-annual mode or Pacific Basin Mode (POB) that has similar dynamics to ENSO, but that emerges under a cooler mean state than 

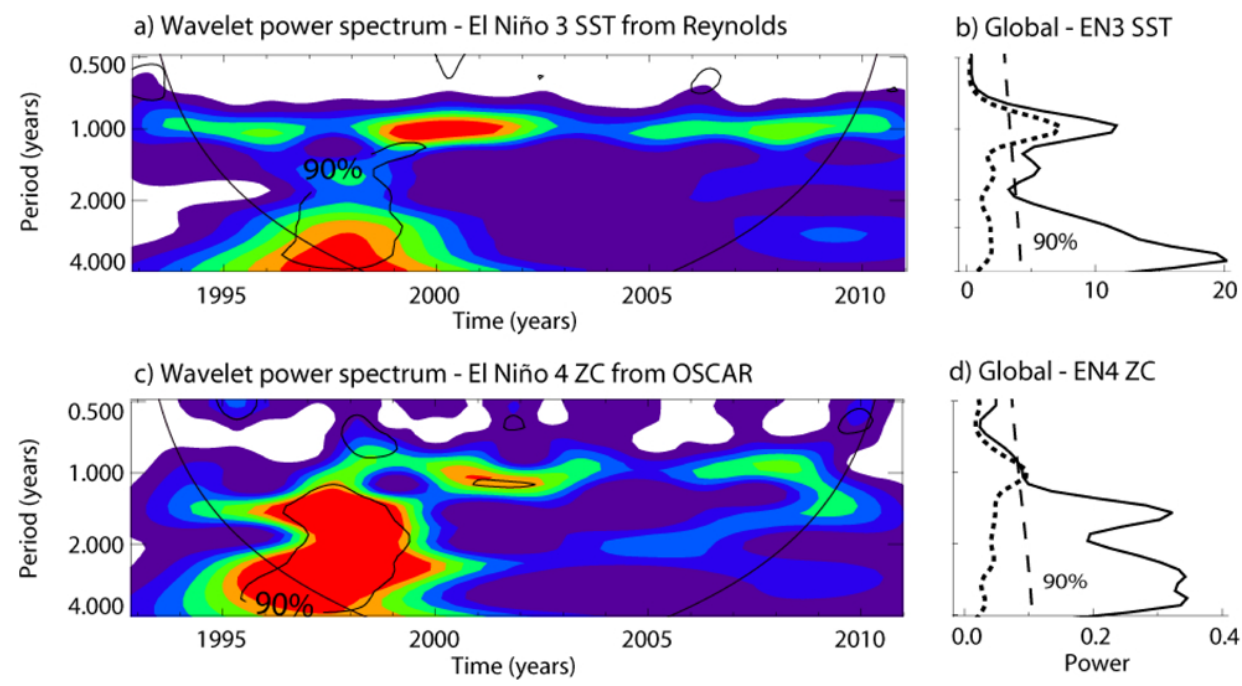

e) Average Variance

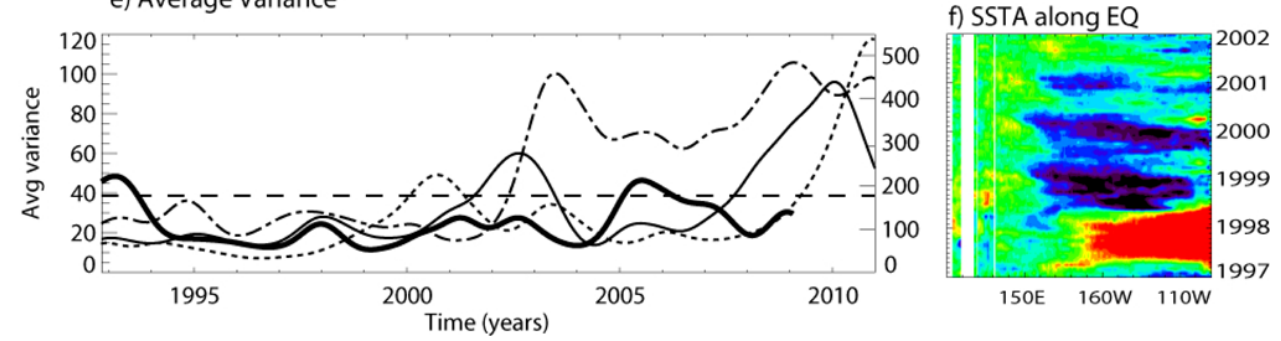

Fig. 1. Wavelet analysis of the sea surface temperature (SST) from Reynolds (NINO3 region) and of the zonal current (ZC) from the OSCAR data set (NINO4 region) for the period October 1992 to December 2010. (a, c) Wavelet power spectrum; black line represents the $90 \%$ confidence spectrum. (b, d) Global wavelet spectrum, solid line is for the period 1992-1999 and dotted line is for the period 2000-2008. The dashed line indicates the $90 \%$ confidence level for the period 1992-1999. (e) Averaged variance of the high-frequency variability relative to the low-frequency variability (i.e. (scale average[0.5-1.5] yr)/(scale average[2-7] yr) $\times 100$ ) for: SST over the NINO3 region (dot-dash line, left scale), SST over the NINO4 region (dotted line, left scale) and ZC over the NINO4 region (solid line, right scale). Dashed line is the $90 \%$ confidence spectrum associated with SST over the NINO3 region. (f) Howmoller for SST anomalies along the Equator for the period 1997-2001 (seasonal cycle from 1982 to 1996).

normal. Kang et al. (2004) demonstrate that such mode is associated with the dominance of the zonal advective feedback over the thermocline feedback in the ENSO dynamics. The existence of such mode of variability has been suggested in former modeling studies (Zebiak, 1984; Jin and Neelin, 1993; Mantua and Battisti, 1995; Périgaud and Dewitte, 1996; Wu and Kirtman, 2005; Dewitte et al., 2007). In particular, in simple shallow water models, it is related to the resonant mode of the tropical Pacific basin that results from the free propagation of Kelvin and Rossby waves and their reflections at the meridional boundaries. Such resonant mode has a frequency close to 9 months and is prominent in the $\mathrm{Ze}$ biak and Cane (1987) type of model (hereafter CZ model), resulting in unrealistic simulated zonal current anomalies in particular (Périgaud and Dewitte, 1996). It has also been suggested that the near-annual mode can interact with ENSO and destabilize the ENSO mode or act as a noise maker to the tropical Pacific, resulting in ENSO modulation (Dewitte et al., 2007).
Despite its theoretical existence (Kang et al., 2004), the analysis of the near-annual mode from observed data has been difficult because it can merge with the seasonal cycle or be eclipsed by the ENSO mode. During cool periods, it can show up as fast westward propagation of negative SST anomalies, like after the 1997/98 El Niño when three consecutive "beams" of cool waters could be observed between 1999 and 2001 (cf. Fig. 1f). During warm periods, like what happened in the early 1990s, Jin et al. (2003) showed that the variability of the fast mode can emerge as miniEl Niño events. In the light of these observations, Kang et al. (2004) used the conceptual model of An and Jin (2001) to demonstrate that the prominence of near-annual variability is related to the increased contribution of anomalous advection of mean temperature to the rate of SST changes (i.e. zonal advective feedback). Dewitte et al. (2007) further show, based on the analysis of a coupled general circulation model (CGCM) simulation, that near-annual variability is also favored by non-linear zonal advection, stressing the importance of surface current variability in the western Pacific and 
mean state. In particular, the zonal SST gradient across the equatorial Pacific controls the strength of the zonal advective feedback through anomalous advection of total temperature and therefore the near-annual activity.

In this paper, we take advantage of the comprehensive satellite data sets of the last decade to document the nearannual variability in the equatorial Pacific. This period is chosen for two reasons: (1) Quality observations with good coverage and high-resolution sampling in time are available. (2) This decade was preceded by the strong 1997/98 El Niño that was followed by prolonged La Niña conditions. This may have contributed to the cooler mean state of the eastern equatorial Pacific in 2000-2008 as compared to the period 1980-1996, which is favorable to the emergence of the nearannual mode (Kang et al., 2004). In addition, this period was characterized by weaker interannual variability than the former period, manifested as increased occurrence of Modoki El Niño (Yeh et al., 2009) and a tendency towards a warmer mean state in the warm pool region (Cravatte et al., 2009). This may have favored the zonal advection processes through increase in zonal SST gradient across the equatorial Pacific, and therefore the development of the near-annual variability.

This paper is organized as follows: Sect. 2 describes the data sets and the methods used in this study. Section 3 is dedicated to identifying the near-annual variability from the satellite data. Section 4 is a discussion with concluding remarks.

\section{Data and methods description}

\subsection{Data}

The zonal and meridional winds from CERSAT (Centre ERS d'Archivage et de Traitement) were used in this study for the period 2000-2008 (www.ifremer.fr/cersat; CERSAT, 2002). The sea surface temperature was provided by RSS (Remote Sensing Sytems) and the Reynolds SST was also used. Zonal and meridional surface currents were obtained from the Ocean Surface Current Products Analyses - Real time (OSCAR) project (Bonjean and Lagerloef, 2002). Fiveday averages were used for winds, sea surface temperature and surface current. Weekly sea level anomaly was provided by the portal Archiving, Validation and Interpretation of Satellite Oceanographic data (AVISO). We performed a spline interpolation over the weekly sea level anomaly data to obtain 5-day means over the period of study (2000-2008).

Oceanic reanalysis data from the SODA (Simple Ocean Data Assimilation) system were also used (Carton and Giese, 2008). The version 2.1.6 was used in this study.

\subsection{Methods}

Our method for diagnosing the near-annual variability is based on the covariance analysis or singular value decomposition (SVD) analysis (Bretherton et al., 1992) of zonal current and zonal wind stress anomalies, considering that the near-annual mode has a clear signature in equatorial zonal current (Périgaud and Dewitte, 1996) and that it is driven to a large extent by zonal advection of mean temperature (Kang et al., 2004). The SVD technique allows capturing the time/space modes that maximize the covariance between two data sets. In that sense, it is similar to an EOF (which is based on the covariance matrix of a single field), but for each mode, one obtains two time series that, if they are highly correlated, may indicate a physically coupled mode.

The time series associated to the SVD modes are analyzed through wavelet decomposition (Torrence and Compo, 1998) to track changes in the frequency and amplitude in the frequency band of interest. Composite analysis is also used to identify a "canonical" near-annual cycle following Jin et al. (2003).

\section{Results}

In order to illustrate further that 2000-2008 is characterized by an enhanced variability in the near-annual frequency band, the SVD analysis is applied to the SODA outputs for two different periods. Figure 2 presents the patterns of the modes resulting from the SVD between wind stress and zonal current anomalies for the periods 1993-1999 and 20002008. For 1993-1999, the dominant mode explains $68 \%$ of the covariance and is characterized by a basin-wide structure for zonal current with westward current anomalies associated with westerlies. The dominant frequency associated to this mode lies in the interannual frequency band (2-7 yr), indicating that the mode pattern is representative of the 1997/98 El Niño. When the SVD is performed over the 2000-2008 period, the mode pattern changes significantly with the zonal current pattern having a zonal seesaw structure with westward (eastward) current anomalies in the western (eastern) Pacific. The pattern for zonal wind stress is somewhat similar to the one for 1993-1999, although the peak anomalies in the western Pacific is slightly moved south of the Equator. The other striking difference between the SVD mode characteristics between 1993-1999 and 2000-2008 periods is the relatively high variability in the near-annual frequency band for the 2000-2008 period (Fig. 2f). A peak emerges at $\sim 1 \mathrm{yr}$ for both zonal wind stress and zonal current, which is above the $90 \%$ confidence level. A similar feature emerges for the results of the SVD performed from the satellite observations (Fig. 3). The 1-yr period peak is even more prominent (Fig. 3c). This supports that the near-annual mode is enhanced over the period 2000-2008. The scale averaged time series for wind stress and zonal current anomalies within the $[0.5-1.5] \mathrm{yr}^{-1}$ frequency band reveal that the near-annual mode is most active in 2000-2003 (not shown). This period is used to build a composite of the evolution of the nearannual mode for SST, zonal current, wind stress and sea level. The three warm mature phases in January of 2000 , 

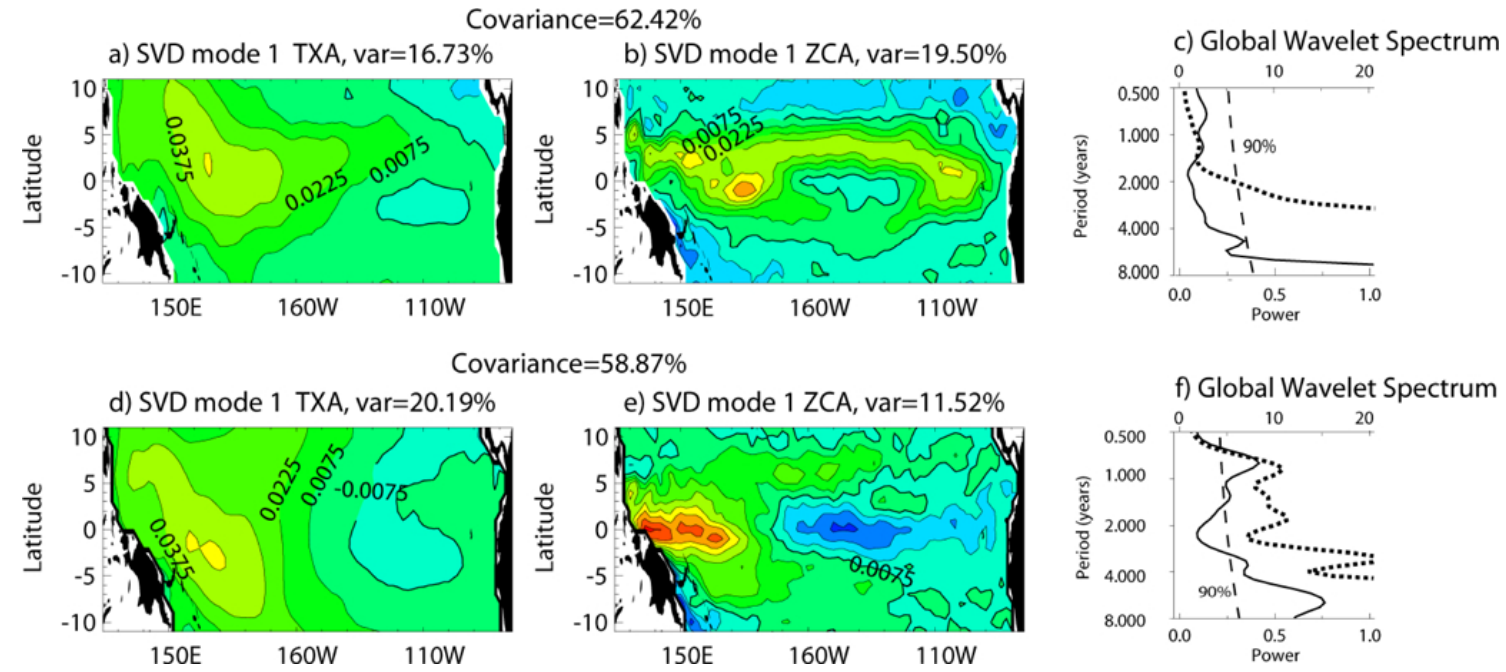

Fig. 2. First mode resulting from the SVD between wind stress and zonal current anomalies: (a) to (c) for the period from January 1993 to December 1999, and from (d) to (f) for the period from January 2000 to December 2008. Data are from SODA. The panels on the left-hand side and in the middle display the spatial pattern for zonal wind stress and zonal current, respectively. The panels on the right-hand side display the global wavelet spectrum of the time series associated with the first SVD mode: solid line for zonal wind stress (lower scale) and thick dotted line for zonal current (upper scale), dashed line is the $90 \%$ confidence level for wind stress and thick dashed line is $90 \%$ confidence level for zonal current. Contour interval $(\mathrm{CI})=0.015$ units. Percentage of explained variance is indicated above each map.
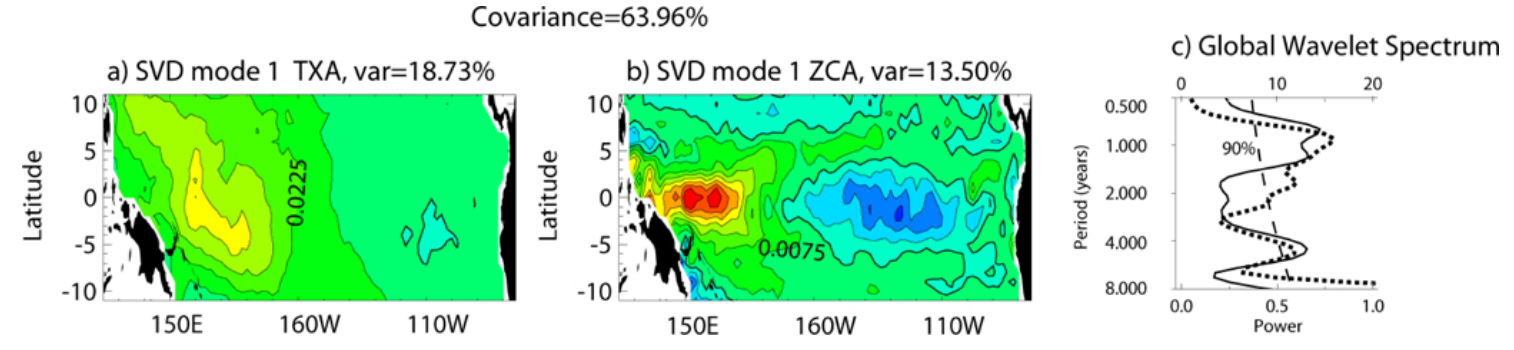

Fig. 3. Same as Fig. 2 but for the SVD analysis between QuikSCAT wind stress (TXA) and OSCAR zonal current anomalies (ZCA) for the period from January 2000 to December 2004.

2001, and July 2002; and the three cold mature phases in July of 2000, 2001, and January 2002 are selected. The composite analysis considers conditions 2 months before the mature phases, at the mature phase, and 2 and 4 months afterwards as the difference between warm and cold conditions. Figure 4 presents the composite evolution of the near-annual mode. Two months before the mature phase, the SST pattern has its center located in the far eastern Pacific while the wind stress pattern exhibits westerly wind anomalies in the western $\mathrm{Pa}$ cific and trade wind anomalies in the eastern Pacific. The sea level pattern mimics the SST, suggesting that SSTs are driven by vertical advection at this stage. At the peak phase the SST anomaly has expanded westward concomitantly with westward zonal current anomalies in the western Pacific that may have driven SST change through zonal advection of mean temperature. The positive sea level anomaly also expands westward at the peak phase. Two months later, at the transition phase, anomalous zonal currents become negative over the eastern Pacific while SST anomalies have propagated to the western Pacific. The sea level anomaly pattern consists in downwelling Rossby wave in the eastern Pacific supposedly resulting from the reflection of the positive sea level anomaly at the eastern boundary during the peak phase. The surface currents from the eastern Pacific enhance and expand the cold SST anomalies by means of an anomalous cold advection from the eastern equatorial Pacific to the central to western Pacific and lead the equatorial SST anomalies into the cold phase. At four month lag, the patterns have almost reversed sign compared to the situation at minus 2 month lag. These results reveal that the residual of the mean seasonal cycle behaves as a coupled mode having similar dynamics as ENSO, which traduces the enhancement of the near-annual variability over this period. 

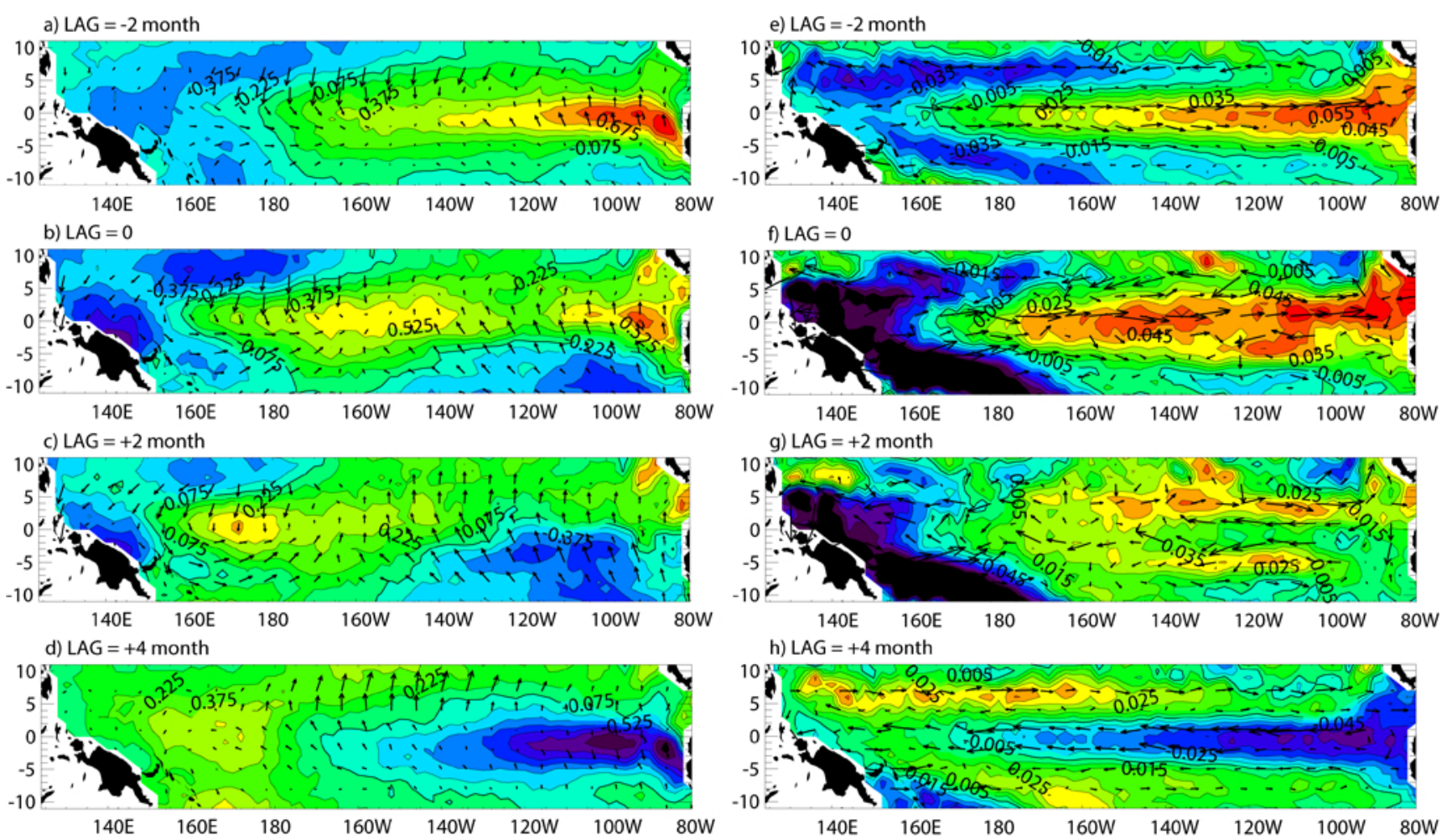

h) $L A G=+4$ month

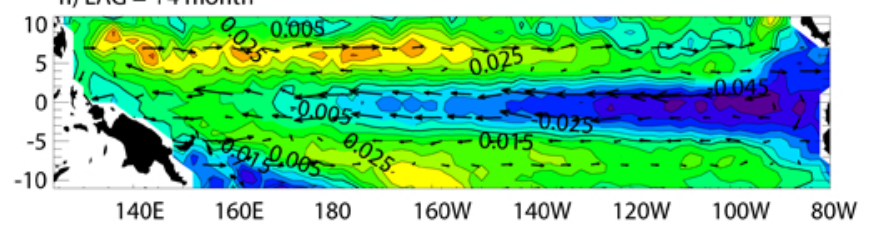

Fig. 4. (a-d) Composites of SST and wind stress anomalies, and (e-h) sea level and surface current anomalies at (a), (e) 2 months before the mature phase of warm SST condition, (b), (f) mature phase, (c), (g) 2 months after the mature phase, and (d), (h) 4 months after the mature phase. Contour interval $(\mathrm{CI})=0.15$ units for SSTA and $\mathrm{CI}=0.01$ units for sea level anomalies. Units in ${ }^{\circ} \mathrm{C}$ for SSTA and $\mathrm{m}$ for sea level anomalies.

a)

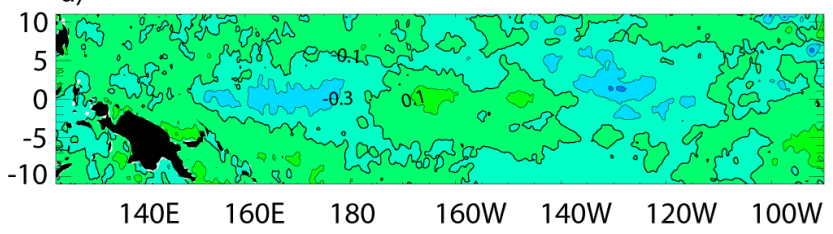

b)

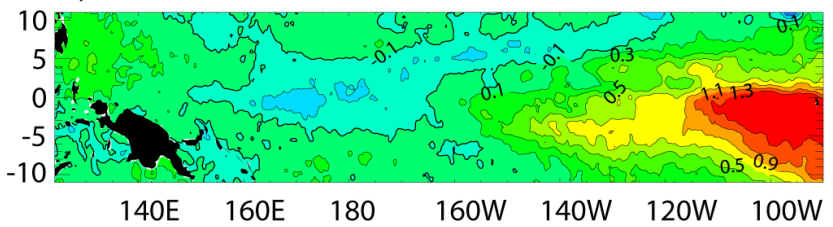

Fig. 5. Maps of weighted skewness of the Reynolds SST anomalies for (a) the period 2000-2008 and (b) the period 1982-1999. $\mathrm{CI}=0.2$ units for SST. Units are ${ }^{\circ} \mathrm{C}$.

\section{Discussion and conclusion}

The last decade experienced a significant change in interannual variability, evidenced as an increased occurrence of El Niño Modoki events (Yeh et al., 2009; Lee and McPhaden, 2010). Because El Niño Modoki events have their maximum amplitude in the central Pacific and are characterized by the maintenance of a zonal SST gradient across the Pacific, periods of enhanced occurrence of such events correspond to periods of relative enhancement of the near-annual mode, which is largely driven by the zonal advective process (Kang et al., 2004). The covariance analysis between SST and zonal current anomalies is used to diagnose the near-annual mode activity. It is shown that it is characterized by a well-defined zonal seesaw zonal current pattern that favors the convergence near the eastern edge of the warm pool and thereby the maintenance of the warm pool. The analysis also reveals that its activity is enhanced over 2000-2004, which allows building a composite of its evolution from satellite observations (SST, zonal current, sea level and wind stress). The composite reveals a clear coupled nature involving equatorial wave dynamics that is comparable to what happens during the "conventional" El Niño cycle. However, conversely to the ENSO cycle, the near-annual mode is characterized by a sort of symmetry that prevents any residual effects on the longer timescales of variability, which may favor its maintenance over an extended period of time. As an illustration we present Fig. 5, which displays the weighted skewness (defined as $m_{3} / m_{2}$, where $m_{k}=\sum_{i=1}^{N}\left(x_{i}-\bar{x}\right)^{k} / N ; x_{i}$ is the $i$-th observations, $\bar{x}$ is the mean, and $N$ is the number of observations) of the SST anomalies for the two periods 1982-2009 and 
2000-2008. It indicates that the positive El Niño asymmetry in the eastern Pacific (An and Jin, 2004) has disappeared over the period 2000-2008. This indicates that both the El Niño Modoki and the near-annual mode have no asymmetry and suggests that the coexistence of both modes of variability may be favored. Further studies are required to evaluate to which extent periods of increased occurrence of El Niño Modiki events are associated to enhance activity of the nearannual mode. This can be addressed by a simulations model that realistically simulates those types of events ( $\mathrm{Yu}$ and Kim, 2010). This is planned for future work.

Acknowledgements. The authors would like to thank the two anonymous reviewers for their constructive comments. The authors also thank IRD for supporting this work.

\section{References}

An, S. I. and Jin, F. F.: Collective Role of Thermocline and Zonal Advective Feedbacks in the ENSO Mode, J. Climate, 14, 34213432, 2001.

An, S. I. and Jin, F. F.: Nonlinearity and asymmetry of ENSO, J. Climate, 17, 2399-2412, 2004.

Ashok, K., Behera, S. K., Rao, S. A., Weng, H., and Yamagata, T.: El Niño Modoki and its possible teleconnection, J. Geophys. Res., 112, C11007, doi:10.1029/2006JC003798, 2007.

Bonjean, F. and Lagerloef, G. S. E.: Diagnostic model and analysis of the surface currents in the tropical Pacific Ocean, J. Phys. Oceanogr., 32, 2938-2954, 2002.

Bretherton, C. S., Smith, C., and Wallace, J. M.: An intercomparison of methods for finding coupled patterns in climate data, $\mathrm{J}$. Climate, 5, 541-560, 1992.

Carton, J. A. and Giese, B. S.: A reanalysis of ocean climate using Simple Ocean Data Assimilation (SODA), Mon. Weather Rev., 136, 2999-3017, 2008.

CERSAT: Mean wind fields (MWF product) - User Manual, Volume 1: QuikSCAT. C2-MUT-W-04-IF, CERSAT - IFREMER (http://www.ifremer/cersat.fr), 2002.

Cibot, C., Maisonnave, E., Terray, L., and Dewitte, B.: Mechanisms of tropical Pacific interannual-to-decadal variability in the ARPEGE/ORCA global coupled model, Clim. Dynam., 24, 823842, doi:10.1007/s00382-004-0513-y, 2005.

Cravatte S., Delcroix, T., Zhang, D., McPhaden, M., and Leloup, J.: Observed freshening and warming of the western Pacific warm pool, Clim. Dynam., 33, 565-589, doi:10.1007/s00382009-0526-7, 2009.

Dewitte B., Cibot, C., Perigaud, C., An, S.-I., and Terray, L.: Interaction between Near-Annual and ENSO Modes in a CGCM Simulation: Role of the Equatorial Background Mean State, J. Climate, 20, 1035-1052, 2007.

Dewitte B., Purca, S., Illig, S., Renault, L., and Giese, B.: Low frequency modulation of the intraseasonal equatorial Kelvin wave activity in the Pacific Ocean from SODA: 1958-2001, J. Climate, 21, 6060-6069, 2008.

Flügel, M. and Chang, P.: Does the predictability of ENSO depend on the seasonal cycle?, J. Atmos. Sci., 55, 3230-3243, 1998.
Galanti, E. and Tziperman, E.: ENSO's phase locking to the seasonal cycle in the fast SST, fast wave, and mixed mode regimes, J. Atmos. Sci., 57, 2936-2950, 2000.

Jin, E. K., Kinter III, J. L., Wang, B., Park, C.-K., Kang, I.-S., Kirtman, B. P., Kug, J.-S., Kumar, A., Luo, J.-J., Schemm, J., Shukla, J., and Yamagata, T.: Current status of ENSO prediction skill in coupled ocean-atmosphere model, Clim. Dynam., 31, 647-666, doi:10.1007/s00382008-0397-3, 2008.

Jin, F.-F and Neelin J. D.: Modes of interannual tropical ocean atmosphere interaction - a unified view. Part I: numerical results, J. Atmos. Sci., 50, 3477-3503, 1993.

Jin, F.-F., Neelin, D. J., and Ghil, M.: El Niño on the devil's staircase: Annual subharmonic steps to chaos, Science, 264, 70-72, 1994.

Jin, F.-F., Kug, J. S., An, S.-I., and Kang, I. S.: A near-annual coupled ocean-atmosphere mode in the equatorial Pacific Ocean, Geophys. Res. Lett., 30, 1080, doi:10.1029/2002GL015983, 2003.

Kang, I.-S., Kug, J.-S., An, S.-I., and Jin, F.-F.: A near-annual Pacific Ocean basin mode, J. Climate, 17, 2478-2488, 2004.

Lee, T. and McPhaden, M. J.: Increasing intensity of El Niño in the central equatorial Pacific, Geophys. Res. Lett., 37, L14603, doi:10.1029/2010GL044007, 2010.

Mantua, N. J. and Battisti, D. S.: Aperiodic Variability in the Zebiak-Cane Coupled Ocean-Atmosphere Model: Air-sea Interaction in the Western Equatorial Pacific, J. Climate, 8, 2897 2927, 1995.

Neelin, J. D., Jin, F.-F., and Syu, H.-H.: Variations in ENSO phase locking, J. Climate, 13, 2570-2590, 2000.

Périgaud, C. and Dewitte, B.: El Niño-La Niña events simulated with Cane and Zebiak's model and observed with satellite and in situ data: Part I: Model Data Comparison, J. Climate, 9, 66-84, 1996.

Philander, S. G.: El Niño and La Niña, J. Atmos. Sci., 42, 26522662, 1985.

Philander, S. G.: El Niño, La Niña and the Southern Oscillation, Academic Press, 289 pp., 1990.

Rodgers, K. B., Friederichs, P., and Latif, M.: Tropical Pacific decadal variability and its relation to decadal modulation of ENSO, J. Climate, 17, 3761-3774, 2004.

Ropelewski, C. F., Halpert, M. S., and Wang, X.: Observed tropospheric biennial variability and its relationship to the Southern Oscillation, J. Climate, 5, 594-614, 1992.

Sun, F. and Yu, J.-Y.: A 10-15 year Modulation Cycle of ENSO Intensity, J. Climate, 22, 1718-1735, 2009.

Timmermann, A., Jin, F.-F., and Abshagen, J.: A nonlinear theory for El Niño bursting, J. Atmos. Sci., 60, 152-165, 2003.

Torrence, C. and Compo, G. P.: A Practical Guide to Wavelet Analysis, B. Am. Meteorol. Soc., 79, 61-78, 1998.

Tourre, Y. M., Kushnir, Y., and White, W. B.: Evolution of interdecadal variability in sea level pressure, sea surface temperature, and upper ocean temperature over the Pacific Ocean, J. Phys. Oceanogr., 29, 1528-1541, 1999.

Yeh S.-W., Kug, S.-J., Dewitte, B., Kwon, M.-H., Kirtman, B. P., and Jin, F.-F.: El Niño in a changing climate, Nature, 461, 511514, 2009.

Yu, J.-Y. and Kim, S. T.: Identification of central-Pacific and eastern-Pacific types of El Niño in IPCC-AR4 models, Geophys. Res. Lett., 37, L15705, doi:10.1029/2010GL044082, 2010. 
Zebiak, S. E.: Tropical atmosphere-ocean interaction and the El Niño/Southern Oscillation phenomenon, Ph.D. dissertation, MIT, 1984.

Zebiak, S. E. and Cane, M. A.: A model El Niño-Southern Oscillation, Mon. Weather Rev., 115, 2262-2278, 1987.

Zhang, R.-H., Rothstein, L. M., and Busalacchi, A. J.: Interannual and decadal variability of the subsurface thermal structure in the Pacific Ocean, Clim. Dynam., 15, 703-717, 1999.
Wu, R. and Kirtman, B. P.: Near-Annual SST Variability in the Equatorial Pacific in a Coupled General Circulation Model, J. Climate, 18, 4454-4473, 2005. 